erty we are to maintain. Associated with this process are the same sort of valuation problems the economists deal with when they study the functioning of the economic system as a connected whole and perhaps an attempt should be made, therefore, to solve these problems along the same lines economists have been using in investigating the forces that determine prices of commodities and of capital. Professor Knight's suggestions regarding the treatment of economic data in general, above mentioned, are obviously along these lines.

Aside from the fact that this treatise is abundantly full of significant ideas and case material that will be exceptionally useful in developing a theory of property valuation, it also shows how the broad general economic tendencies influencing property valuation (whatever they may be) have been modified by the courts and the various experts that have appeared before the courts both at certain times and historically.

\title{
A REPLY
}

JAMTES C. BonbrighT*

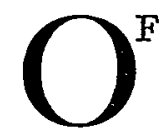
F ALI the reviews of our treatise on Valuation that have come to my attention, the one by Professor Nerlove interests me the most. Previous reviewers have discussed the specific conclusions and recommendations of our case studies, expressing sometimes agreement, sometimes dissent. So far as I am aware, however, none of them has taken issue with our general method of approach. But Professor Nerlove strikes at the very heart of the treatise by challenging its whole "functional" method of analysis. Since his position has broad implications for legal economics, and indeed for the social sciences in general, I gladly add these comments at the invitation of the editors.

Let me confess, however, that Professor Nerlove has expressed his criticisms in a form that makes an effective answer very difficult. In the first place, instead of furnishing a "bill of particulars," he presents a blanket indictment of the methodology of the treatise and of the results obtained therefrom, citing no case discussions in support of the counts of the indictment. In the second place, he declines to commit himself by affirmative or negative answers to the basic questions that he raises, even though most of these questions have already been raised and discussed at length in the treatise and in the supplementary published studies noted in our preface. He therefore throws back upon the author

* Professor of Finance, Columbia University. It should be noted that Professor Nerlove's footnotes were added after Professor Bonbright had written his reply. (Editor). 
the burden of reestablishing, within a short reply, proof which the author and his collaborators attempted to adduce in a book of eleven hundred pages fortified by three special monographs and twenty-odd articles in the law reviews.

For example, we accept the position, expressed by Justice Brandeis in the case to which Professor Nerlove refers, that "value is a word of many meanings" and that the appropriate meaning cannot be selected without reference to the particular social purpose that the valuation is designed to serve. Does the reviewer deny this thesis? By implication he seems to do so; yet he avoids a denial in so many words. To be sure, he insists that "value" cannot be defined by sole reference to the purpose or objective of the law suit. But no sane man would take a contrary position-not even the author of this treatise!

Writing under these limitations, which threaten to turn the discussion into mere shadow boxing, I may now take up Professor Nerlove's points in the order in which he raises them.

We are first reproached for a failure fully to recognize the need of "logically differentiating" between three divisions of economics distinguished by Professor Frank H. Knight-divisions which presumably should have been set off by separate portions of the treatise. Had we followed this methodology, the reviewer believes that we would not have been led to expect as much as we seem to have expected from orthodox economic theory; and we would then have been "adequately aware" of the limitations of this type of theory. I wonder what parts of the treatise reveal to the reviewer any inadequate awareness of the limitations of standard theory as a guide to the solution of the problems of valuation faced by the courts. In fact, it was our very conviction of these limitations that led us to redefine the problems in terms of a so-called "functional approach."

In the next paragraph, Professor Nerlove regrets that our "thoughts" on the proper definition of the word, "value," do not "seem sufficiently precise to afford a useful body of standards." This is indeed a serious indictment; for it indicates either that our whole methodology is unsound or else that our applications of the method are inept. In the absence of specific references to our actual treatment of the litigated cases, I can hardly answer so broad a charge. But since the reviewer implies that the basic trouble is with our faulty, "functional" approach, let me suggest that he put the point to the test by applying one or all of his three proposed alternative methods to a few of the cases discussed in the treatisefor example, to the Southwestern Bell Telephone rate case, the Standard 
Oil-Southern Pacific damage case, and the recent New Jersey Railroad Tax cases. While I feel sure that with adequate study Professor Nerlove could offer more acceptable solutions than we have been able to offer (especially so since for some situations we have been content to raise issues without offering any positive solutions whatever), I suspect that he would be led to take essentially the same "functional approach" that is taken in our treatise.

The reviewer devotes his next few paragraphs to an exposition of the main viewpoint of our study. With qualifications his exposition is correct; but these qualifications are serious. We by no means assert that a consistent body of thought dealing with property valuation cannot be developed by identifying "value" with current market price. On the contrary, we indicate that such a body of thought not only can be, but has been, developed. ${ }^{x}$ Our point was simply that the resulting theory, by virtue of its limited objectives, offers no solution to one of the most critical questions presented in a legal valuation-the question as to how "value" should be defined and measured in the light of the special objective of the appraisal.

Again, we do not contend that "value" should be defined as "an attribute of the particular purpose" of the valuation, since such a contention would make no more sense to us than it does to Professor Nerlove. In measuring the length of my bedroom for the purpose of guiding me in the choice of a rug of suitable size, I would not construe "Iength" as an attribute of this purpose. But in interpreting the ambiguous phrase "length of my room," as well as in deciding what tools of measurement to use, I would certainly be influenced by the specific objective that led me to take this special interest in cameral dimensions.

The core of Professor Nerlove's adverse attitude toward our "method of approach" is to be found, I surmise, in the paragraph introducing his quotation from Professor Bridgeman. By questions rather than by affirmative statements he implies that the concept of property value should be "solely associated with the operation involved in" the measurement of its quantitative amount rather than "with the purpose for which a particular valuation is being made." Already our treatise gives much attention to "operational" value definitions." To be sure, the courts, by expressing distrust of appraisal formulas and by their liberal rulings on the admissibility of conflicting types of offered "evidence," have not often been friendly to operational definitions; and I think the recent trend of the

× P. ri66.

2E.g., pp. Ir80-Ir8I and index references under "Formulas v. judgment, use of." 
cases, with a few partial exceptions, has been in the other direction. In certain types of litigation, notably in tax valuations of highly marketable securities and other property, we ourselves have defended what is in effect an operational definition of value. ${ }^{3}$ Indeed, a strong, though not a conclusive, case could be made for bolder extensions of this practice.

What surprises me, however, is the reviewer's suggestion of a false antithesis between operational definitions, and definitions chosen with express reference to the objectives of the valuation. For, even if the courts were invariably to define "value" to mean whatever figure, expressed in monetary terms, is reached by the correct application of a specific technique of appraisal, they would still face the necessity of choosing that technique, and hence that definition, which is best calculated to serve the social objectives of the particular law under which some kind of an appraisal is required. Does Professor Nerlove mean to imply that a single, definitive, method of appraisal should serve all legal purposes, or even that it is applicable to all types of property when valued for the same purpose? The acceptance of such a contention would revolutionize the whole theory and practice of appraisal, not only for the courts but also for the professional appraisers. I can hardly believe that the reviewer holds any such view. Yet, if he does not hold it, I fail to see the significance of his proposal to adopt an operational definition of value instead of a functional definition.

In a later paragraph, the reviewer takes us to task for our "objection" to Justice Brandeis' prudent investment standard of rate making-an objection that he thinks we would have found "not wholly justified" had we only given adequate answers to the questions posed in his review. So far from objecting to this proposed standard, we warmly defended it not only in the treatise but, in extenso, by a whole monograph written as a supplement to our basic study. ${ }^{4}$ Indeed, the very position taken by the Justice in the opinion which Professor Nerlove cites is the position of our treatise from which the reviewer appears to dissent. Incidentally, the "prudent investment" standard as expounded by Justice Brandeis does not invoke an operational concept of value, although an operational definition, consistent with the Justice's basic principle, might well be devised.

Professor Nerlove raises the question as to whether we contend that "a property has as many different values as there are legal purposes for valuing it." Construing this question to ask whether the same property at the same time must be assigned a different value for every different
3 P. 1075.
4 Bauer and Gold, Public Utility Vahuation. 
legal purpose, I think the answer should be clearly in the negative. As indicated on page II 67 of the treatise, several of the current definitions of value can be put to a variety of uses, and the acceptance of one definition, for example in a particular type of damage case, does not preclude the acceptance of the same definition, for instance in a particular type of tax case. On the other hand, different definitions of value may be required for various types of property that are to be valued for the same purpose; and they may even be required for the same type of property valued for the same purpose but held by different types of individuals. 5 Hence, my answer to the above question will afford small comfort to those who seek a solution for the terribly complex problems of modern legal valuation in the development of some great, consistent system of value theory.

With the last part of the review, which suggests three other methods of approach to a theory of valuation, I have no quarrel. Already the first of these methods has long been accepted by economic theorists and is now being applied to great advantage by appraisal experts, such as F. M. Babcock. As the review indicates, our own study tries to interrelate all three of them, although I dare say that our attempt has been crude and faulty. To be sure, none of these three methods of approach will supply answers to the types of questions emphasized in our book. But this statement is not meant to condemn them or to belittle their usefulness. Practical problems in the social sciences must be attacked from many different angles and by many cross-classifications of the issues involved.

\title{
A CONSTITUTIONAI RATE BASE
}

\author{
JaMies Barclay Sattr*
}

I

$\mathrm{F}$ TOR many years valuation has been a contentious subject. The tremendous importance of the existence of effective regulatory power to the citizen at his fireside and to government in action has been attached in some way to valuation for purposes of discussion. The varieties of the adhesions are as numerous as the expressions. While legal restraints are involved, necessarily the subject vahue carries economic features. Great names have imposed stifling effect on refutation by those often characterized as lawyer-trained. Because, it is said, legal rules cannot equate economic balances. But the true economic standard does not

5 Pp. $29 x-3$ I8.

* Professor of Law, University of Kansas. 